\title{
Fracture Resistance of Endodontically Treated Anterior Teeth Restored with Different Post Systems: An In Vitro Study
}

\author{
(D) Abdulrahman FADAG, (1) Maged NEGM, (1) Abdulaziz SAMRAN, (D) Ahlam SAMRAN, \\ (1) Giraldine AHMED, (1D) Ali ALQERBAN, (1) Mutlu ÖZCAN
}

\section{ABSTRACT}

Objective: This in vitro study aimed to evaluate the fracture resistance of endodontically treated maxillary central incisors with different post systems.

Methods: Fifty-six extracted intact maxillary permanent central incisors were used, treated endodontically (except for the control group), and distributed into the following seven test groups $(n=8)$ depending on the post type: UHT (control group: root-filled teeth without endodontic post), ZRP (prefabricated zirconia post), GFP (prefabricated glass fiber post), CFP (prefabricated carbon fiber post), CPC (custom-made cast post and core), TIP (prefabricated titanium post), and MIP (prefabricated mixed post). The specimens were loaded in a universal testing machine until fracture occurrence. Failure loads were then analyzed with one-way analysis of variance (ANOVA), followed by multiple comparisons by using Tukey's honest significant difference test $(a=0.05)$.

Results: Mean (SD) failure loads for groups ranged from $524 \pm 73.2 \mathrm{~N}$ for CPC to $764.1 \pm 156 \mathrm{~N}$ for GFP. Oneway ANOVA showed significant differences in terms of fracture resistances among groups $(P<0.001)$. Tukey's honest significant difference test showed significant differences in fracture resistance within groups $(P \leq 0.05)$, whereas no difference was observed between the UHT (control group) and CFP and CPC groups ( $P \geq 0.05)$.

Please cite this article as: Fadag A, Negm M, Samran A, Samran A, Ahmed G, Alqerban $A$, et al. Fracture resistance of endodontically treated anterior teeth restored with different post systems: an in vitro study. Eur Endod J 2018; 3: 174-8

From the Department of Fixed Prosthodontics, Restorative and Prosthetic Dental Sciences (A.S. $\square$ asamran@dau.edu.sa, A.S.) School of Dentistry, Ibb University, Ibb, Yemen, School of Dentistry, Dar Al-Uloom University, Saudi Arabia; Department of Endodontics, (A.F, M.N, G.A.), Faculty of Dentistry, Ibb University, Ibb, Yemen, Faculty of Oral and Dental Medicine, Cairo University, Cairo, Egypt; Department of Preventive Dental Sciences, (A.A.), Prince Sattam Bin Abdulaziz University, Saudi Arabia and Dar Al-Uloom University, Saudi Arabia; Department of Clinic for Fixed and Removable Prosthodontics and Dental Materials Science (M.Ö.), Dental Materials Unit, University of Zürich, Zürich, Switzerland

Received 08 June 2018, last revision received 13 June 2018, accepted 13 June 2018

Published online: 07 September 2018 DOI 10.14744/eej.2018.70299

Conclusion: Endodontically treated teeth restored with zirconia post, glass fiber post, titanium post, or mixed post were more resistant to fracture loads compared with those that were not restored (control group) or restored with either carbon fiber post or cast post and core.

Keywords: Cast posts, fiber posts, fracture resistance, titanium posts, zirconia posts

\section{HIGHLIGHTS}

- Considering fracture resistance, ETT restored with zirconia, glass fiber, titanium, or mixed posts were the most resistant to fracture load.

- ETT restored without posts were the least resistant to fracture load.

- In terms of fracture resistance, ETT restored with carbon fiber post or cast post and core were better than those without posts and lower than those restored with zirconia, glass fiber, titanium, or mixed posts. have revealed that anterior teeth are subject to high risks of failure (7-10). On the basis of the abovementioned studies, we can conclude that selection of inadequate restorative option can cause vertical root fractures (11). Rigid posts, such as titanium, stainless steel, and zirconia, possess high elastic moduli of 110,200 , and $300 \mathrm{GPa}$, respectively, which exceed that of dentin (18 $\mathrm{GPa})$ and can cause fracture $(10,12)$. For rigid posts, stress will transmit internally and concentrate toward the apical level, thereby increasing the risk of vertical root fracture, which signifies catastrophic failure $(13,14)$. Fiber-reinforced composite post have been proposed as an alternative to cast metal posts (15). According to their low elasticity, adhesive resin cement may act as a shock absorber and decrease the risk of root fractures $(3,5,16)$. This material has manifested satisfactory survival rates over relatively long follow-up periods (17). However, conflicting results have 
been observed in previous studies comparing prefabricated posts and custom-made cast post and cores (18-22). Teeth restored with custom-made cast post and core systems showed higher loads before fracturing. In this case, the fracture often becomes more catastrophic (14). On the other hand, teeth restored with prefabricated post systems showed low fracture resistance and the fracture can often be restored (1). The difference in the mechanical behavior of teeth restored with different post systems have been attributed to differences in stiffness, which affects stress distribution in teeth (18-22). The mechanism of the effects of different post systems on fracture resistance of ETT remains unclear. Therefore, in this study, we aimed to evaluate the fracture resistance of endodontically treated maxillary central incisors with different post systems. The null hypothesis of the study states that different post systems will not affect the fracture resistance of endodontically treated maxillary central incisors.

\section{MATERIALS AND METHODS}

\section{Test groups}

Fifty-six recently extracted caries-free maxillary central incisors were selected and stored in $0.1 \%$ thymol solution at $25^{\circ} \mathrm{C}$ until use. Teeth were selected by measuring the apicoincisal length and buccopalatal and mesiodistal widths (in $\mathrm{mm}$ ), allowing a maximum deviation of $10 \%$ from the average by using a digital caliper (Links Brand; Harbin Metering Instrument Works, Harbin, China). ANOVA was used for determining significant differences among the measurements for each group $(P \leq 0.05)$. Radiograph evaluation of each tooth was performed to ensure that no internal resorption or obstruction existed within the canal system. The teeth were cleaned with a hand scaler and stored at room temperature during the study. Ethical approval was received from the local ethics committee (COD 02-2016). On the basis of an effect size of 1.4, an 80-sample size calculation power, and a significance level of $5 \%(P<0.05)$, the sample size was 8 per group, resulting in a total of 56 specimens. Root canals ( $1 \mathrm{~mm}$ shortened to roots apices) were cleaned and shaped using the step-back technique to apical size (40) and then obturated with gutta-percha points (Spident, Meta Biomed Co., Incheon, Korea) and a eugenol-free epoxyamine resin sealer (ADSEAL; Dentsply Meta Biomed Co., Incheon, Korea) using the lateral condensation technique. The teeth were stored in distilled water at room temperature for 3 days. To simulate the periodontal ligament situation, the roots were immersed in melted wax at a depth of $2 \mathrm{~mm}$ below the cementoenamel junction (CEJ) and then embedded in acrylic resin blocks. Afterward, teeth roots were embedded in auto-polymerizing resin (Idofast Unipol, Unidesa-Odi, Madrid, Spain) up to 2-mm apex of CEJ and oriented with their long axes perpendicular to the horizon using a custom-made parallelometer. Each root was removed from the resin block upon appearance of primary signs of polymerization. The wax spacer was replaced by a silicon-based impression material (Light body, Speedex; Coltene, Altstätten, Switzerland), which was injected into the acrylic resin. Then, the tooth was reinserted into the resin block, and excess impression materials were removed using a surgical blade. Samples were randomly divided into seven groups ( $n=8)$ according to the type of the intracanal post, if any, as follows:
UHT: control group; root-filled teeth without endodontic posts.

ZRP: root-filled teeth with prefabricated zirconia post (Nordin, Swiss Dental Products of Distinction, Chailly/Montreux, Switzerland).

GFP: root-filled teeth with prefabricated glass fiber post (Rely $X, 3 M$ ESPE, USA).

CFP: root-filled teeth with prefabricated carbon fiber post (Nordin, Swiss Dental Products of Distinction, Chailly/Montreux, Switzerland).

CPC: root-filled teeth with custom-made cast post and core consisting of $\mathrm{CoCr}$ alloy (Wironit, Bego, Bremen, Germany).

TIP: root-filled teeth with prefabricated titanium post (Dentatus, New York, USA).

MIP: root-filled teeth with prefabricated mixed glass fiber and carbon fiber posts (Angelus, Londrina, PR, Brazil).

Root canal filling materials (gutta-percha and sealer) were removed (except UHT) using number 1, 2, 3, and 4 Gates Glidden burs (Maillefer, Ballaigues, Switzerland). Post spaces were prepared using a low-speed corresponding drill provided by the post manufacturer to achieve a post space length of $10 \mathrm{~mm}$ in all groups. All posts were air-borne particle-abraded with $50-\mu \mathrm{m}$ alumina particles (Aluminum Oxide Abrasive; Heraeus Kulzer) for $5 \mathrm{~s}$ at $0.25 \mathrm{MPa}$ and ultrasonically cleaned in $96 \%$ isopropanol for $3 \mathrm{~min}$. The post spaces were then rinsed with $3 \%$ sodium hypochlorite solution, irrigated with $70 \%$ ethanol, and dried with absorbent paper points. The walls of the post spaces were etched with 37\% phosphoric acid (Meta Etchant; Meta Biomed Co, Ltd) for $15 \mathrm{~s}$, rinsed with water spray, and air-dried. The posts were coated with freshly mixed self-adhesive resin cement (RelyX Unicem; 3M ESPE) that were applied using disposable microbrushes. Each post was seated with finger pressure for $10 \mathrm{~s}$. Excess resin cements were spread to cover the occlusal part of the post. Light-polymerizing composite resin cores (Filtek Z250 XT; 3M ESPE) were fabricated according to the manufacturer's instructions. All procedures were performed by the same operator.

\section{Loading of specimens}

All specimens were quasi-statically tested with a universal testing machine (Lloyd Instruments Ltd; Fareham; UK) until fracture occurrence (in Newton). The crosshead speed was 1 $\mathrm{mm} / \mathrm{min}$ at an angle of $135^{\circ}$ to the long axis of the tooth at the center of the palatal fossa (Fig. 1). Failure of loading was recorded when a sudden dip was observed in the force versus time graph.

The failure mode was determined by visual inspection. Two typical root fracture modes were determined as follows (Fig. 2): specimens presenting a cervical third fracture were classified as a favorable mode, whereas those presenting middle and apical third fracture were classified as an unfavorable or catastrophic mode $(1,3)$. 


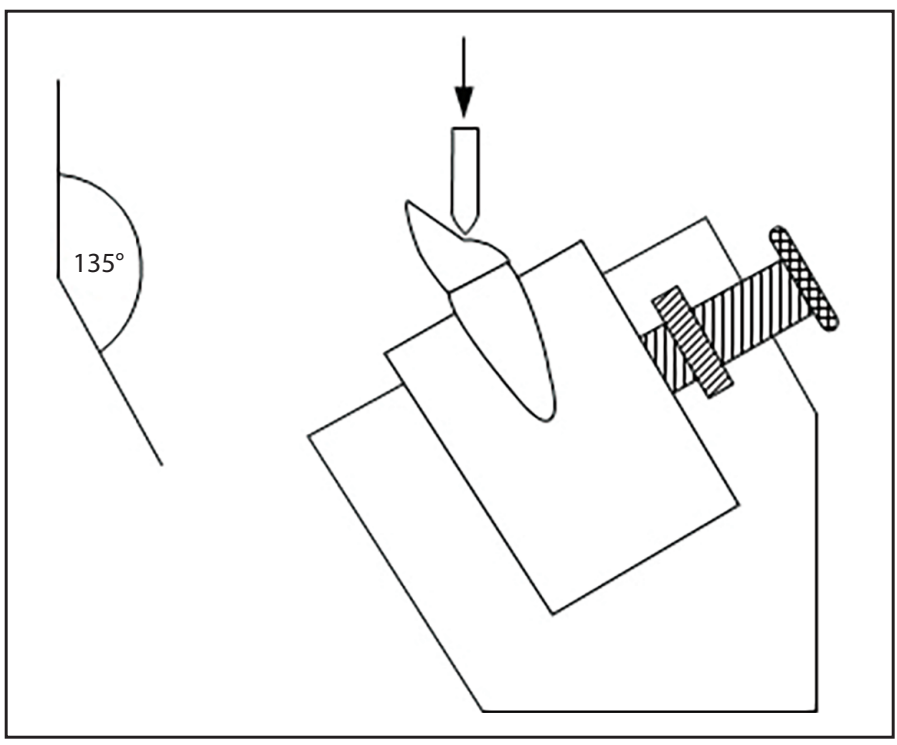

Figure 1. Schematic view of the apparatus for fracture testing with a specimen mounted in the universal testing machine at angle of $135^{\circ}$ relation to the long axis of the posts

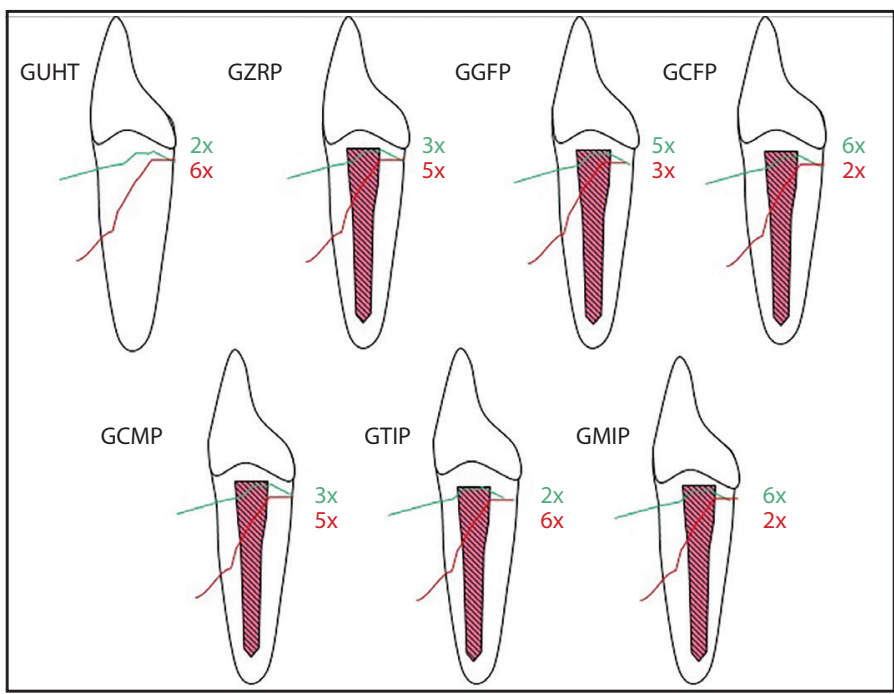

Figure 2. Fracture patterns and the frequency of each pattern in study groups

\section{Statistical analysis}

Fracture load data were analyzed using SPSS software (SPSS version 18.0 for Windows). Data were explored for normality using the Anderson-Darling test, which showed normally distributed data. Across all seven groups, fracture load data were analyzed using one-way ANOVA followed by multiple comparisons with Tukey's honest significant difference test $(a=0.05)$. Failure modes were recorded and statistically analyzed with chi-square $\left(\chi^{2}\right)$ test among groups for determining the correlation between post systems and failure mode (favorable or restorable/unfavorable or non-restorable).

\section{RESULTS}

Table 1 presents the means (M) and standard deviations (SD) of fracture loads in Newton. Load ranged from $524 \pm 73.2$ to $764.1 \pm 156 \mathrm{~N}$. The mean fracture loads to fracture recorded in groups CFP, UHT, and CPC (562.8, 551.2, and 524, respectively)

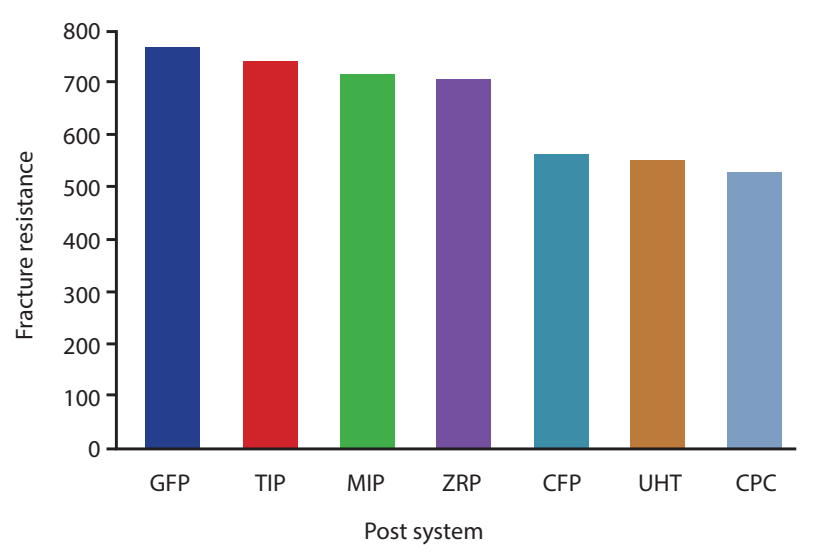

Figure 3. The overall fracture strength (in N) of the test groups ranked from highest to lowest

TABLE 1. Fracture loads in $N($ Means $\pm S D)$

\begin{tabular}{lc}
\hline Group & Fracture loads \\
\hline $\begin{array}{l}\text { UHT (control group): healthy root-filled } \\
\text { teeth without endodontic posts }\end{array}$ & $551.2 \pm 69.1 \mathrm{~A}$ \\
$\begin{array}{l}\text { ZRP: root-filled teeth with prefabricated } \\
\text { zirconia post }\end{array}$ & $704.8 \pm 112.8 \mathrm{~B}$ \\
$\begin{array}{l}\text { GFP: root-filled teeth with prefabricated } \\
\text { glass fiber post }\end{array}$ & $764 . \pm 156 \mathrm{~B}$ \\
$\begin{array}{l}\text { CFP: root-filled teeth with prefabricated } \\
\text { carbon fiber post }\end{array}$ & $562.8 \pm 131 \mathrm{~A}$ \\
$\begin{array}{l}\text { CPC: root-filled teeth with } \\
\text { custom-made post }\end{array}$ & $524.0 \pm 73 \mathrm{~A}$ \\
$\begin{array}{l}\text { TIP: root-filled teeth with prefabricated } \\
\text { titanium post }\end{array}$ & $736.2 \pm 83.9 \mathrm{~B}$ \\
MIP: root-filled teeth with prefabricated \\
mix post
\end{tabular}

Means with different superscript letters $(A, B)$ in each column significantly differ at $95 \%$ confidence level

TABLE 2. Fracture mode of each group

\begin{tabular}{lccccccc}
\hline Fracture mode & \multicolumn{7}{c}{ Groups } \\
\cline { 2 - 7 } & UHT & ZRP & GFP & CFP & CPC & TIP & MIP \\
\hline Favourable & 2 & 3 & 5 & 6 & 3 & 2 & 6 \\
& $(25 \%)$ & $(37.5 \%)$ & $(62.5 \%)$ & $(75 \%)$ & $(37.5 \%)$ & $(25 \%)$ & $(75 \%)$ \\
Unfavourable & 6 & 5 & 3 & 2 & 5 & 6 & 2 \\
& $(75 \%)$ & $(62.5 \%)$ & $(37.5 \%)$ & $(25 \%)$ & $(62.5 \%)$ & $(75 \%)$ & $(25 \%)$ \\
\hline
\end{tabular}

were significantly lower than those recorded in GFP, TIP, MIP, and ZRP groups (764, 736.2, 714.1, and 704.8, respectively) $(\mathrm{P}<0.05)$ (Fig. 3).

In groups CFP, GFP, and MIP, most of the specimens showed a favorable fracture mode $(75 \%, 62.5 \%$, and $75 \%$ respectively). Conversely, in groups UHT, ZRP, CPC, and TIP, most of the specimens manifested an unfavorable fracture mode (Table 2).

\section{DISCUSSION}

In the present study, we investigated the influence of different post systems on fracture resistance of maxillary central 
incisors. The use of natural teeth is a reliable method for fracture testing and has also been used in some studies $(1,23,24)$. To mimic clinical conditions, all teeth were first subjected to endodontic therapy, wherein post spaces were first subjected to irrigation with sodium hypochlorite solution during canal preparation and, subsequently, sealed with an endodontic sealer during canal obturation. Maxillary central incisors teeth were selected as relatively no differences were observed between the mesiodistal crown diameters of the left and right incisors (25). A self-adhesive resin cement was selected for its higher push-out bond strength than conventional dual-polymerizing resin cements (26). A composite resin core material was used in this study owing to its higher fracture resistance than other core materials, such as amalgam and glass ionomer; this result is observed because of the stronger union between the core and the tooth structure in composite resin core material, which can be established using adhesive bonding agents, than with other core materials (1).

The null hypothesis, which supposes that different post systems will not affect the fracture resistance of endodontically treated maxillary central incisors, was rejected. The different post systems significantly influenced the final fracture resistance $(P \leq 0.05)$. The fracture resistance of all specimens ranged from $524 \pm 73.2$ to $764.1 \pm 156 \mathrm{~N}$; this range is comparable to the results of previous in vitro studies (27-30). CPC yielded the lowest fracture resistance values, whereas GFP showed a significantly higher fracture resistance. These results may explain how different post systems enhance fracture resistance of ETT. In the present study, RelyX glass fiber posts exhibited the highest fracture resistance with a mean value of $764.1 \pm 156 \mathrm{~N}$. This finding is in accordance with that of Aggarwa et al. (31) and Madfa et al. (32). They reported that compared with other dental posts, glass fiber posts generate the least amount of stress concentration at the middle and apical parts of posts and are the best options for restoration of badly decayed teeth. Conversely, this finding disagrees with the results of Beck et al.(33), who reported significantly lower fracture load of glass fiber posts than of zirconia posts. This difference between results may be attributed to variations in core materials used, composite resin and zirconia cores, and sizes of the tested posts. Among the posts used in the present study, casted metal posts recorded the lowest fracture resistance values. This result agrees with the findings of Giovani et al. (22), who revealed that roots restored with glass fiber posts showed higher fracture resistance than cast posts of the same length. This finding may be attributed to the fact that the elasticity modulus of glass fiber posts is similar to that of dentin, which can better absorb forces concentrated along the root and can decrease the probability of fracture (34). However, this result is in contrast with those of Kaur et al. (35), who reported that cast $\mathrm{NiCr}$ post and core specimens feature higher mean fracture resistance than glass fiber and titanium posts. This finding may be attributed to the nature of teeth and core type. Carbon fiber posts are stiff and possess approximately 10 -fold higher modulus elasticity than dentin $(12,36)$. This fact may confirm results of the present study in which teeth reinforced with carbon fiber posts showed lower fracture resistance than those restored with glass fiber posts.
The UHT (control group), CPC, and CFP groups had the lowest fracture resistance values, which can be attributed to several factors. In the UHT (control group), where there was no resin cement, the absence of resin cement means the absence of a monoblock system. The presence of resin cement with fiber posts created a unique system called a monoblock system where the resin cement can bond to the dentin and fiber posts. In the CPC group, because of the high modulus of elasticity in such posts, they can directly transfer the applied forces to the root and cause fracture. Carbon fiber posts are quite stiff and strong, to a degree that is comparable to that of several posts made of metal, and possess a modulus approximately 10 times higher than dentin (36). This fact may confirm the results in the present study in which teeth reinforced with carbon fiber posts showed lower fracture resistance than those restored with glass fiber posts.

In the present study, Chi-square $\left(\chi^{2}\right)$ analysis indicated statistically significant differences in the failure modes among groups $(P=0.023)(1,3)$. Most specimens with glass fiber, carbon fiber, and mixed posts showed favorable failure modes, whereas unfavorable or catastrophic failures were shown mostly with the control, titanium, zirconium, and cast post groups. These findings agree with those of different studies and can be attributed to the high elasticity modulus of metal posts $(1,3,36$, 37). Under stress, rigid posts absorb no force but transmit it to less rigid structures, in this case dentin, that possess a lower elasticity modulus.

Finally, we can conclude that the use of zirconia, glass fiber, titanium, or mixed posts can improve fracture resistance of ETT. Limitations of this study may include the incorporation of a single load in the fracture test and making the access opening as small as possible. Dynamic loading, temperature effects, and oral environment effects were excluded but may also be considered as limitations. To mimic intraoral conditions, further studies should be conducted with thermocycling and dynamic fatigue loading. Further investigations on other teeth in the dental arch (molars or premolar teeth) are recommended to complement the present study results. Use of visual inspection to determine failure mode can also be considered a limitation of the present study.

\section{CONCLUSION}

Within the limitations of this in vitro study, the following can be concluded:

- ETT restored with zirconia, glass fiber, titanium, and mix posts were more resistant to fracture load than unrestored teeth (control group) or those restored with carbon fiber posts or cast posts and core.

- Because of their rigidity, restoring ETT with carbon fiber posts or cast posts and core can lead to tooth fracture.

- Presence of fiber posts changes the failure mode, and the fracture pattern was mainly favorable.

\section{Disclosures}

Conflict of interest: No conflict of interest was declared by the authors.

Ethics Committee Approval: Dar Aluloom University, Saudi Arabia. 
Peer-review: Externally peer-reviewed.

Financial Disclosure: The authors declared that this study has received no financial support.

Authorship contributions: Concept - A.F.; Design - M.N.; Supervision - G.A.; Fundings - A.F.; Materials - A.F.; Data collection \&/or processing - A.F.; Analysis and/or interpretation - A.S.; Literature search - A.S.; Writing - A.S.; Critical Review - A.A., M.Ö.; Final proof review - A.A.

\section{REFERENCES}

1. Samran A, El Bahra S, Kern M. The influence of substance loss and ferrule height on the fracture resistance of endodontically treated premolars. An in vitro study. Dent Mater 2013; 29(12):1280-6.

2. Abduljawad M, Samran A, Kadour J, Al-Afandi M1, Ghazal M, Kern M. Effect of fiber posts on the fracture resistance of endodontically treated anterior teeth with cervical cavities: An in vitro study. J Prosthet Dent 2016; 116(1):80-4.

3. Samran A, Al-Afandi M, Kadour JA, Kern M. Effect of ferrule location on the fracture resistance of crowned mandibular premolars: An in vitro study. J Prosthet Dent 2015; 114(1):86-91.

4. Aggarwal R, Gupta S, Tandan A, Gupta NK, Dwivedi R, Aggarwal R. Comparative evaluation of fracture resistance of various post systems using different luting agents under tangential loading. J Oral Biol Craniofac Res 2013; 3(2):63-7.

5. Karzoun W, Abdulkarim A, Samran A, Kern M. Fracture strength of endodontically treated maxillary premolars supported by a horizontal glass fiber post: an in vitro study. J Endod 2015; 41(6):907-12.

6. Theodosopoulou JN, Chochlidakis KM. A systematic review of dowel (post) and core materials and systems. J Prosthodont 2009; 18(6):464-72.

7. Naumann M, Koelpin M, Beuer F, Meyer-Lueckel H. 10-year survival evaluation for glass-fiber-supported postendodontic restoration: a prospective observational clinical study. J Endod 2012; 38(4):432-5.

8. Caplan D. Glass-fiber-reinforced posts may be more likely to fail in anterior teeth than in posterior teeth over a 10-year period. J Evid Based Dent Pract 2013; 13(1):33-4.

9. Naumann M, Blankenstein F, Kiessling S, Dietrich T. Risk factors for failure of glass fiber-reinforced composite post restorations: a prospective observational clinical study. Eur J Oral Sci 2005; 113(6):519-24.

10. Schmitter M, Hamadi K, Rammelsberg P. Survival of two post systemsfive- year results of a randomized clinical trial. Quintessence Int 2011; 42(10):843-50.

11. Lertchirakarn V, Palamara JE, Messer HH. Patterns of vertical root fracture: factors affecting stress distribution in the root canal. J Endod 2003; 29(8):523-8.

12. Dean JP, Jeansonne BG, Sarkar N. In vitro evaluation of a carbon fiber post. J Endod 1998; 24(12):807-10.

13. Dietschi D, Duc O, Krejci I, Sadan A. Biomechanical considerations for the restoration of endodontically treated teeth: a systematic review of the literature--Part 1. Composition and micro- and macrostructure alterations. Quintessence Int 2007; 38(9):733-43.

14. Fokkinga WA, Kreulen CM, Vallittu PK, Creugers NH. A structured analysis of in vitro failure loads and failure modes of fiber, metal, and ceramic post-and-core systems. Int J Prosthodont 2004; 17(4):476-82.

15. Goracci C, Ferrari M. Current perspectives on post systems: a literature review. Aust Dent J 2011;56 Suppl 1:77-83.

16. Mendoza DB, Eakle WS, Kahl EA, Ho R. Root reinforcement with a resinbonded preformed post. J Prosthet Dent 1997; 78(1):10-4.

17. Cagidiaco MC, Goracci C, Garcia-Godoy F, Ferrari M. Clinical studies of fiber posts: a literature review. Int J Prosthodont 2008; 21(4):328-36.

18. Torres-Sánchez C, Montoya-Salazar V, Córdoba P, Vélez C, Guzmán-Duran $A$, Gutierrez-Pérez JL, et al. Fracture resistance of endodontically treated teeth restored with glass fiber reinforced posts and cast gold post and cores cemented with three cements. J Prosthet Dent 2013; 110(2):127-33.

19. Martínez-Insua A, da Silva L, Rilo B, Santana U. Comparison of the fracture resistances of pulpless teeth restored with a cast post and core or carbonfiber post with a composite core. J Prosthet Dent 1998; 80(5):527-32.

20. Schmitter M, Lippenberger S, Rues S, Gilde H, Rammelsberg P. Fracture resistance of incisor teeth restored using fibre-reinforced posts and threaded metal posts: effect of post length, location, pretreatment and cementation of the final restoration. Int Endod J 2010; 43(5):436-42.

21. Franco EB, Lins do Valle A, Pompéia Fraga de Almeida AL, Rubo JH, Pereira $J R$. Fracture resistance of endodontically treated teeth restored with glass fiber posts of different lengths. J Prosthet Dent 2014; 111(1):30-4.

22. Giovani $A R$, Vansan $L P$, de Sousa Neto MD, Paulino SM. In vitro fracture resistance of glass-fiber and cast metal posts with different lengths. $J$ Prosthet Dent 2009; 101(3):183-8.

23. Mangold JT, Kern M. Influence of glass-fiber posts on the fracture resistance and failure pattern of endodontically treated premolars with varying substance loss: an in vitro study. J Prosthet Dent 2011; 105(6):387-93.

24. Sherfudhin H, Hobeich J, Carvalho CA, Aboushelib MN, Sadig W, Salameh $Z$. Effect of different ferrule designs on the fracture resistance and failure pattern of endodontically treated teeth restored with fiber posts and allceramic crowns. J Appl Oral Sci 2011; 19(1):28-33.

25. Cesario VA Jr, Latta GH Jr. Relationship between the mesiodistal width of the maxillary central incisor and interpupillary distance. J Prosthet Dent 1984; 52(5):641-3.

26. Pereira JR, Valle AL, Ghizoni JS, Só MV, Ramos MB, Lorenzoni FC. Evaluation of push-out bond strength of four luting agents and SEM observation of the dentine/fibreglass bond interface. Int Endod J 2013; 46(10):982-92.

27. $\mathrm{Ng}$ CC, Dumbrique HB, Al-Bayat Ml, Griggs JA, Wakefield CW. Influence of remaining coronal tooth structure location on the fracture resistance of restored endodontically treated anterior teeth. J Prosthet Dent 2006; 95(4):290-6.

28. Dikbas I, Tanalp J, Ozel E, Koksal T, Ersoy M. Evaluation of the effect of different ferrule designs on the fracture resistance of endodontically treated maxillary central incisors incorporating fiber posts, composite cores and crown restorations. J Contemp Dent Pract 2007; 8(7):62-9.

29. Sirimai S, Riis DN, Morgano SM. An in vitro study of the fracture resistance and the incidence ofvertical root fracture of pulpless teeth restored with six post-and-coresystems. J Prosthet Dent 1999; 81(3):262-9.

30. Maccari PC, Conceição EN, Nunes MF. Fracture resistance of endodontically treated teeth restored with three different prefabricated esthetic posts. J Esthet Restor Dent 2003; 15(1):25-30.

31. Aggarwal S, Garg V. Finite element analysis of stress concentration in three popular brands of fiber posts systems used for maxillary central incisor teeth. J Conserv Dent 2011; 14(3):293-6.

32. Madfa AA, Kadir MR, Kashani J, Saidin S, Sulaiman E, Marhazlinda J, et al. Stress distributions in maxillary central incisors restored with various types of post materials and designs. Med Eng Phys 2014; 36(7):962-7.

33. Beck N, Graef F, Wichmann M, Karl M. In vitro fracture resistance of copymilled zirconia ceramic posts. J Prosthet Dent 2010; 103(1):40-4.

34. Lassila LV, Tanner J, Le Bell AM, Narva K, Vallittu PK. Flexural properties of fiber reinforced root canal posts. Dent Mater 2004; 20(1):29-36.

35. Kaur J, Sharma N, Singh H. In vitro evaluation of glass fiber post. J Clin Exp Dent 2012; 4(4):e204-9. [CrossRef ]

36. Asmussen E, Peutzfeldt A, Heitmann T. Stiffness, elastic limit, and strength of newer types of endodontic posts. J Dent 1999; 27(4):275-8.

37. Bitter K, Noetzel J, Neumann K, Kielbassa AM. Effect of silanization on bond strengths of fiber posts to various resin cements. Quintessence Int 2007; 38(2):121-8. 